\title{
Fiber optic distributed temperature sensing for the determination of air temperature
}

\author{
S. A. P. de Jong, J. D. Slingerland, and N. C. van de Giesen \\ Faculty of Civil Engineering and Geosciences, Delft University of Technology, Delft, the Netherlands \\ Correspondence to: N. C. van de Giesen (n.c.vandegiesen@tudelft.nl)
}

Received: 29 April 2014 - Published in Atmos. Meas. Tech. Discuss.: 23 June 2014

Revised: 13 November 2014 - Accepted: 10 December 2014 - Published: 15 January 2015

\begin{abstract}
This paper describes a method to correct for the effect of solar radiation in atmospheric distributed temperature sensing (DTS) applications. By using two cables with different diameters, one can determine what temperature a zero diameter cable would have. Such a virtual cable would not be affected by solar heating and would take on the temperature of the surrounding air. With two unshielded cable pairs, one black pair and one white pair, good results were obtained given the general consensus that shielding is needed to avoid radiation errors (WMO, 2010). The correlations between standard air temperature measurements and air temperatures derived from both cables of colors had a high correlation coefficient $\left(r^{2}=0.99\right)$ and a RMSE of $0.38^{\circ} \mathrm{C}$, compared to a RMSE of $2.40^{\circ} \mathrm{C}$ for a $3.0 \mathrm{~mm}$ uncorrected black cable. A thin white cable measured temperatures that were close to air temperature measured with a nearby shielded thermometer (RMSE of $0.61^{\circ} \mathrm{C}$ ). The temperatures were measured along horizontal cables with an eye to temperature measurements in urban areas, but the same method can be applied to any atmospheric DTS measurements, and for profile measurements along towers or with balloons and quadcopters.
\end{abstract}

\section{Introduction}

Distributed temperature sensing (DTS) is a technique that allows for measurement of temperature along optical fibers. Laser pulses are shot into the fiber, and backscatter from within the fiber is analyzed. The time of flight then gives the position along the fiber from where the backscatter originated. Analysis of the Raman spectrum of the backscatter allows for the calculation of the temperature at the place where the backscatter originated. Depending on the type of DTS machine used, temperatures can be measured continuously at sub-meter intervals along cables of more than $5 \mathrm{~km}$, with laboratory accuracies up to $0.01{ }^{\circ} \mathrm{C}$ and typical field accuracies of $0.08^{\circ} \mathrm{C}$ (van de Giesen et al., 2012). A good introduction to DTS principles and environmental applications can be found in Selker et al. (2006) and Tyler et al. (2009).

Over the past decade, DTS has found many environmental applications. Applications vary from temperature profiling of the subsurface: borehole observations (Freifeld et al., 2008), soils (Ciocca et al., 2012; Jansen et al., 2011; Sayde et al., 2010; Steele-Dunne et al., 2010); water: estuaries (Henderson et al., 2009), surface/groundwater (Lowry et al., 2007; Mamer and Lowry, 2013), solar ponds (Suárez et al., 2011), streams (Selker et al., 2006; Vogt et al., 2010; Westhoff et al., 2007, 2011) and lakes (Vercauteren et al., 2011; van Emmerik et al., 2013); rocks (Read et al., 2013), ice caves (Curtis and Kyle, 2011), forests (Krause et al., 2013) and infrastructure: dam surveillance (Dornstadter, 1998), sewers (Hoes et al., 2009), electric transmission cables (Yilmaz and Karlik, 2006) and gas pipelines (Tanimola and Hill, 2009).

There are only a few experiments where DTS is used to measure atmospheric temperature (Keller et al., 2011; Petrides et al., 2011; Thomas et al., 2012), since solar heating can have a significant effect. Keller et al. (2011) experimented during nighttime to exclude the effect of short-wave radiation. Petrides et al. (2011) estimated effective shade and concluded that solar radiation is the driving factor in temperature differences. Thomas et al. (2012) observed differences in temperature measurements with black and white cables and suggested that it can be used for setting up an energy balance.

This paper will describe a method to correct for the effect of solar radiation in atmospheric DTS measurements with 


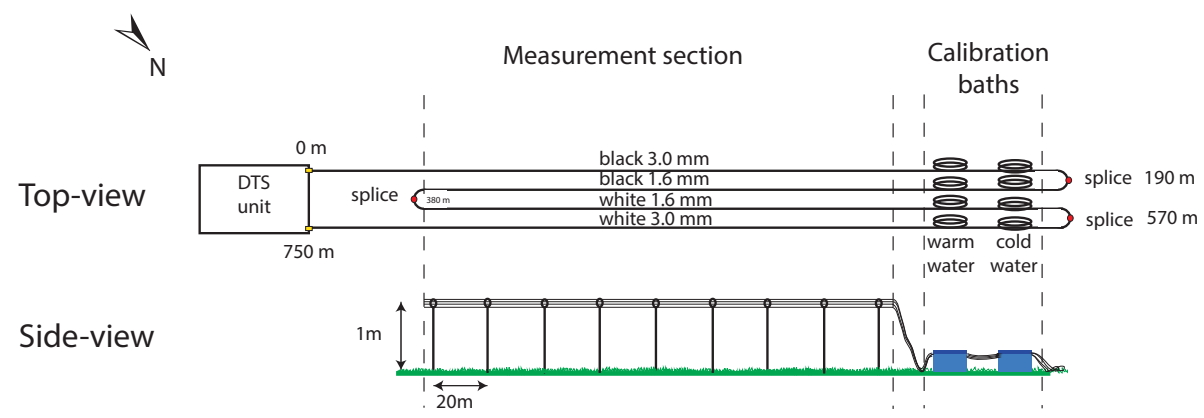

Figure 1. Schematic overview of the experimental setup. The cable exists of four sections (black with diameter 3.0 and $1.6 \mathrm{~mm}$ and white with diameter 3.0 and $1.6 \mathrm{~mm}$ ). In the measurement section the cables are held in open air above a grass field.

the use of fiber optic cables with different diameters. The original objective of the experiment was to test whether air temperature differences in urban landscapes can be measured with reasonable accuracies $\left(1^{\circ} \mathrm{C}\right)$.

\section{Materials and methods}

\subsection{Theory}

Solar radiation causes objects to be warmer than the surrounding air. For this reason, thermometers are traditionally shielded by a screen. For accurate measurements, forced ventilation is necessary, which was not provided in our case (WMO, 2010). The temperature difference between a heated cylinder (or sphere) and the air that moves around it scales with the square root of the diameter (White, 1988). If the diameter of a cylinder were zero, the heat generated by solar radiation would also be zero. Such a zero diameter cylinder would take on the temperature of the surrounding air. One can create a virtual cylinder with zero diameter by extrapolating the temperatures of two cylinders with different diameters. The fiber optic cables used by DTS can be considered to be very long cylinders. When the temperatures of two cables $\left(T_{1}\right.$ and $\left.T_{2}\right)$ with different diameters $\left(d_{1}\right.$ and $\left.d_{2}\right)$ are measured, then the air temperature can be determined by extrapolating to a zero diameter, which results in Eq. (1):

$T_{\text {air }}=T_{2}-\frac{T_{1}-T_{2}}{\sqrt{\frac{d_{1}}{d_{2}}}-1}$.

This idea (G. Campbell, personal communication, 2010) is based on the assumptions of having an infinitely long cylinder, instant redistribution of heat within a cross section of the cylinder, and forced convection on the outside of the cylinder. Forced convection dominates when the buoyancy force parameter, also known as the Archimedes number, Ar, is much smaller than one. For a cylinder of diameter $d(\mathrm{~m})$ we have

$\mathrm{Ar}=\frac{\mathrm{Gr}}{\operatorname{Re}^{2}}=g \cdot \frac{T_{s}-T_{\text {air }}}{T_{\text {air }}} \cdot \frac{d}{v^{2}}$, where $\mathrm{Gr}$ is the Grashof number (dimensionless), Re the Reynolds number (dimensionless), $g$ the acceleration due to gravity $\left(9.8 \mathrm{~m} \mathrm{~s}^{-2}\right), T_{\text {air }}$ the air temperature $(\mathrm{K}), T_{\mathrm{S}}$ the surface temperature of the cable $(\mathrm{K})$ and $v$ the wind speed $\left(\mathrm{m} \mathrm{s}^{-1}\right)$.

\subsection{Experimental setup}

The measurements were taken from 27 April 2011 through 3 May 2011 on a grass field near Delft University of Technology, Delft, the Netherlands (51-59'45.44" N, 4$22^{\prime} 39.56^{\prime \prime} \mathrm{E}$ ). The DTS instrument was a HALO unit (Sensornet, Elstree, UK) with a sampling interval of $2 \mathrm{~m}$ and a measurement interval of $20 \mathrm{~s}$. The fiber optic cables used in this experiment consisted of single (simplex) multi-mode, bend-insensitive optical fibers, tightly packed, protected with Kevlar and a plastic jacket (AFL, South Carolina, USA).

A schematic drawing of the experimental setup is shown in Fig. 1. The cable consisted of four sections: one black with diameter $3.0 \mathrm{~mm}$, one black with diameter $1.6 \mathrm{~mm}$, one white with diameter $3.0 \mathrm{~mm}$ and one white with diameter $1.6 \mathrm{~mm}$. Each section had a length of $190 \mathrm{~m}$. Of each section, $150 \mathrm{~m}$ of fiber optic cable was held in open air, $1 \mathrm{~m}$ above the grass, with the use of pigtail fence posts. The sections were spliced together to enable continuous measurements.

The DTS was operated in a single-ended configuration. For calibration purposes, each section had $20 \mathrm{~m}$ of fiber cable coiled up in a thermally insulated water bath with warm water (average $27^{\circ} \mathrm{C}$ ) and cold water (average $14^{\circ} \mathrm{C}$ ). The setup of baths and splices was such that the cable from each stretch went directly through the two baths without first passing through a splice, thereby avoiding step losses within stretches. The signal was checked to ensure sufficient strength, especially towards the end of the cable. Bath temperatures were measured with the two PT100 thermometers that came with the HALO unit, which have a reported accuracy of $0.1 \mathrm{~K}$. Calibration of the fiber optic cable was based on the method described by Hausner et al. (2011). For each measurement period, the bath temperatures from that same measurement period were used for the calibration. 

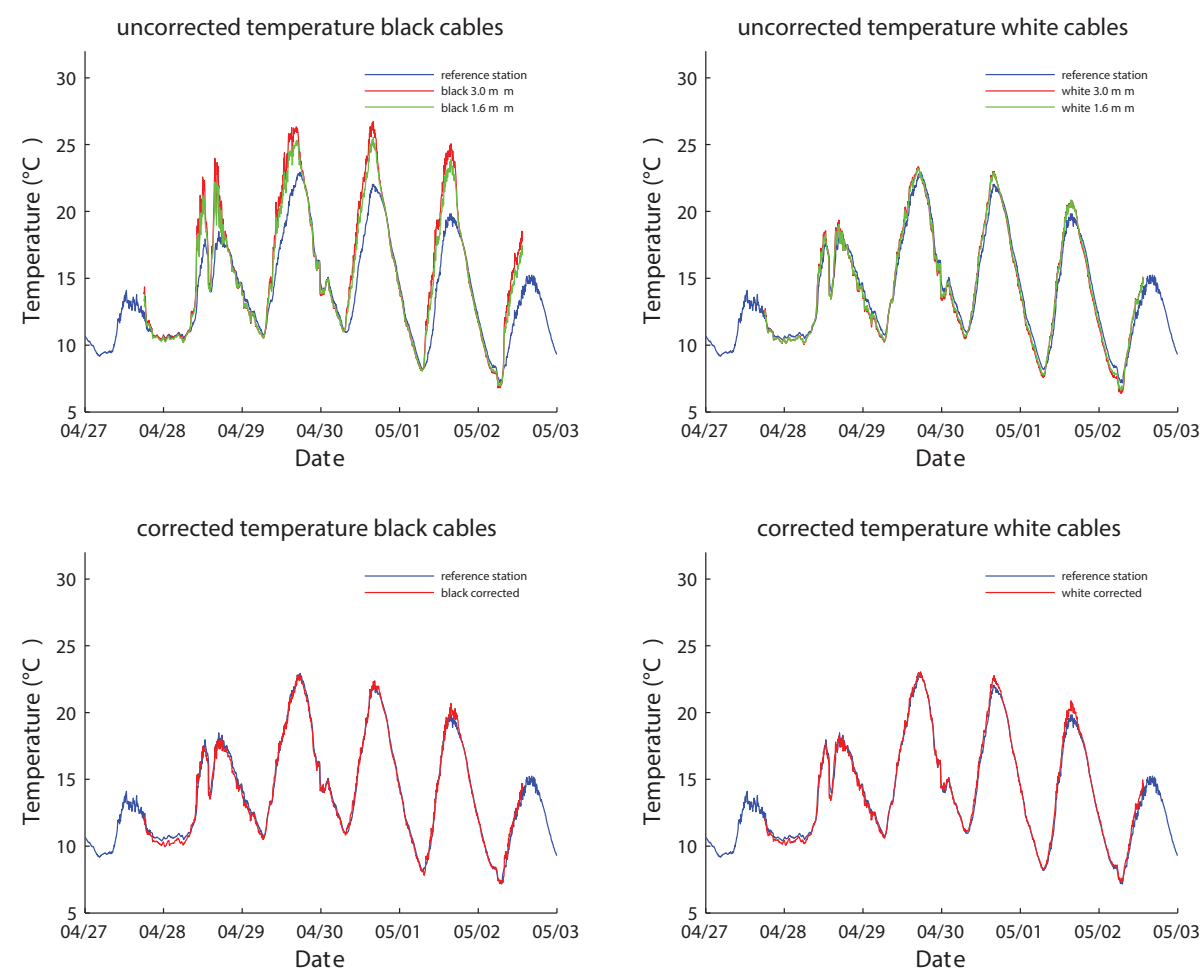

Figure 2. Top: comparison between the reference station and the uncorrected averaged temperature of the black (left) and white (right) cables in the measurement section. Bottom: comparison between the reference station and the corrected temperatures of the black (left) and white (right) cable.

For this analysis, 62 measurement points of each section hanging in the air were averaged to one time series. To improve further the signal to noise ratio, the DTS measurements were averaged over time using an integration time of $5 \mathrm{~min}$. We assume that heat within the cross section of the cable is distributed equally at this timescale.

As a reference station, a HOBO weather station (Onset Computer Corporation, USA) with rain ( $\mathrm{mm})$, temperature $\left({ }^{\circ} \mathrm{C}\right)$, relative humidity $(\%)$ and incoming solar radiation $\left(\mathrm{W} \mathrm{m}^{-2}\right)$ was installed next to the experimental setup. The temperature/RH sensor used was a 12 bit Temperature Smart Sensor (S-THB-M002) with a reported accuracy of $\pm 0.13{ }^{\circ} \mathrm{C}$. The reference station had a measurement interval of $5 \mathrm{~min}$. The sensor was placed inside a HOBO RS1 radiation shield with only natural ventilation.

Wind velocity data measurements, to determine whether the assumption of forced convection was valid, were taken from the closest automated weather station of the Royal Netherlands Meteorological Institute. This station is situated at the airport of Rotterdam (51-57'33.66" N, 4-26'32.66" E), $6 \mathrm{~km}$ from the experiment location. There can be important differences between the wind measured in Rotterdam and the wind at our site, but these data only served as a check to see whether there were no periods without wind $\left(<0.1 \mathrm{~m} \mathrm{~s}^{-1}\right)$.

\section{Results and discussion}

Weather conditions from 27 to 30 April were partly cloudy with a daily maximum incoming solar radiation between 600 and $650 \mathrm{~W} \mathrm{~m}^{-2}$. On 28 April there was a rain event with $2.4 \mathrm{~mm}$ of rain. Conditions from 1 to 3 May were clear and sunny with daily maximum incoming solar radiation between 650 and $750 \mathrm{~W} \mathrm{~m}^{-2}$.

The dominant wind direction was north-east. The wind speed during daytime varied between 3 and $9 \mathrm{~m} \mathrm{~s}^{-1}$, making the assumption of forced convection valid $(\mathrm{Ar}<0.001)$. Note that forced convection will dominate in all but the most extreme natural conditions.

Figure 2 shows the average temperature measured by the black cables and the white cables. The uncorrected temperatures show a clear temperature rise during daytime due to solar heating. This effect is significantly larger for the black cables than for the white cables. During daytime, the black cables show a clear temperature rise due to solar heating. The correlation coefficient $r^{2}$ (see Fig. 3) between the uncorrected temperature of the black 3.0 and $1.6 \mathrm{~mm}$ cable with the reference station is respectively $r^{2}=0.77$ and $r^{2}=0.85$ and a RMSE of 2.40 and $1.80^{\circ} \mathrm{C}$. The uncorrected temperatures of the white 3.0 and $1.6 \mathrm{~mm}$ cable show a correlation of respectively $r^{2}=0.97$ and $r^{2}=0.98$ and a RMSE of 0.74 

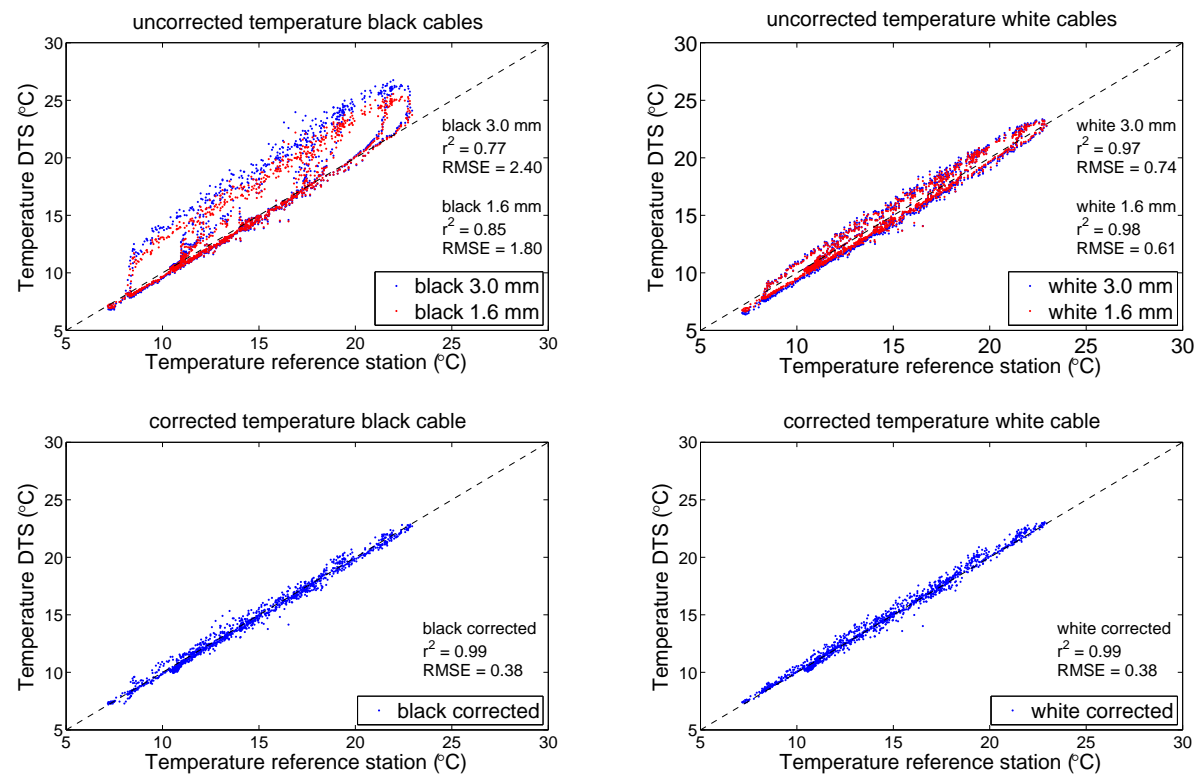

Figure 3. Top: correlations between the temperature measurements of the reference station and the uncorrected temperatures of the black (left) and white (right) table. Bottom: correlation between the temperature measurements of the reference station and the corrected temperatures of the black (left) and white (right) fiber optic cables.

and $0.61{ }^{\circ} \mathrm{C}$. The corrected temperatures of both the white and black cable have an $r^{2}$ of 0.99 and a RMSE of $0.38^{\circ} \mathrm{C}$.

The standard deviations of individual measurements within the stretches were $0.29^{\circ} \mathrm{C}$ for $3.0 \mathrm{~mm}$ white, $0.28^{\circ} \mathrm{C}$ for $1.6 \mathrm{~mm}$ white, $0.39^{\circ} \mathrm{C}$ for $3.0 \mathrm{~mm}$ black, and $0.35^{\circ} \mathrm{C}$ for $1.6 \mathrm{~mm}$ black. The standard deviation of the average of the 62 points would then be between 0.04 and $0.05^{\circ} \mathrm{C}$. It should be noted that the accuracy of the instrument is about $0.02^{\circ} \mathrm{C}$ for a point measurement with perfect calibration and that similar setups have given field accuracies of $0.1^{\circ} \mathrm{C}$ (Hausner et al., 2011). So the measured variation is likely to be also caused by real temperature differences along the cable, caused by uneven heating/cooling.

\section{Conclusions}

Distributed temperature sensing (DTS) of atmospheric temperature profiles is hindered by solar heating, which may lead to significant deviations from the true air temperature. For atmospheric measurements with DTS we showed that it is possible to correct for solar heating and find a good estimation for the air temperature, by using cables with different diameters.

The corrected temperatures matched the temperature measurements of the reference station with a RMSE of $0.38^{\circ} \mathrm{C}$. The reference measurement took place without forced ventilation so the RMSE of the reference station could easily account for half the RMSE. The method used to calculate the air temperature is independent of the color of the cable. If it is not possible to apply different sizes of cable in a setup in an atmospheric DTS application, the use of a thin white fiber optic cable is a reasonably good alternative.

The experiment started out with the question of whether corrected DTS air temperature measurements would have a reasonable accuracy to measure temperatures across urban landscapes. The results show that this is indeed the case and they were actually better than we expected at the onset $\left(1^{\circ} \mathrm{C}\right)$. In hindsight, we would have installed a better reference temperature measurement device because we can not say whether the reference was truly better than the DTS-derived temperatures. Although we can not conclude this from the results, it may be possible to further reduce systematic errors, in which case this method would become valuable for vertical atmospheric soundings with DTS from balloons, quadcopters, or towers. White would be preferable over black, given the lower standard deviation within stretches.

Edited by: M. Hamilton

\section{References}

Ciocca, F., Lunati, I., Van de Giesen, N. C., and Parlange, M. B.: Heated optical fiber for distributed soil-moisture measurements: A lysimeter experiment, Vadose Zone J., 11, doi:10.2136/vzj2011.0199, 2012.

Curtis, A. and Kyle, P.: Geothermal point sources identified in a fumarolic ice cave on erebus volcano, antarctica using fiber optic distributed temperature sensing, Geophys. Res. Lett., 38, L16802, doi:10.1029/2011GL048272, 2011. 
Dornstadter, M. and Aufleger, D.: The Prospect for Reservoirs in the 21st Century: Proceedings of the Tenth Conference of the BDS Held at the University of Wales, Bangor on 9-12 September 1998, Thomas Telford Publishing, 1998.

Freifeld, B. M., Finsterle, S., Onstott, T. C., Toole, P., and Pratt, L. M.: Ground surface temperature reconstructions: Using in situ estimates for thermal conductivity acquired with a fiber-optic distributed thermal perturbation sensor, Geophys. Res. Lett., 35, L14309, doi:10.1029/2008GL034762, 2008.

Hausner, M. B., Suárez, F., Glander, K. E., Van de Giesen, N., Selker, J. S., and Tyler, S. W.: Calibrating single-ended fiberoptic raman spectra distributed temperature sensing data, Sensors, 11, 10859-10879, doi:10.3390/s111110859, 2011.

Henderson, R. D., Day-Lewis, F. D., and Harvey C. F.: Investigation of aquifer-estuary interaction using wavelet analysis of fiber-optic temperature data, Geophys. Res. Lett., 36, L06403, doi:10.1029/2008GL036926, 2009.

Hoes, O., Schilperoort, R., Luxemburg, W., Clemens, F., and Van de Giesen, N.: Locating illicit connections in storm water sewers using fiber-optic distributed temperature sensing, Water Res., 43, 5187-5197, doi:10.1016/j.watres.2009.08.020, 2009.

Jansen, J., Stive, P., Van de Giesen, N., Tyler, S., Steele-Dunne, S., and Williamson, L.: Estimating soil heat flux using distributed temperature sensing, in: IAHS Publ. 343, 140-144, 2011.

Keller, C. A., Huwald, H., Vollmer, M. K., Wenger, A., Hill, M., Parlange, M. B., and Reimann, S.: Fiber optic distributed temperature sensing for the determination of the nocturnal atmospheric boundary layer height, Atmos. Meas. Tech., 4, 143-149, doi:10.5194/amt-4-143-2011, 2011.

Krause, S., Taylor, S. L., Weatherill, J., Haffenden, A., Levy, A., Cassidy, N. J., and Thomas, P. A.: Fibre-optic distributed temperature sensing for characterizing the impacts of vegetation coverage on thermal patterns in woodlands, Ecohydrology, 6, 754764, doi:10.1002/eco.1296, 2013.

Lowry, C. S., Walker, J. F., Hunt, R. J., and Anderson, M. P.: Identifying spatial variability of groundwater discharge in a wetland stream using a distributed temperature sensor, Water Resour. Res., 43, W10408, doi:10.1029/2007WR006145, 2007.

Mamer, E. A. and Lowry, C. S.: Locating and quantifying spatially distributed groundwater-surface water interactions using temperature signals with paired fiber-optic cables, Water Resour. Res., 49, 7670-7680, doi:10.1002/2013WR014235, 2013.

Petrides, A. C., Huff, J., Arik, A., Van de Giesen, N., Kennedy, A. M., Thomas, C. K., and Selker, J. S.: Shade estimation over streams using distributed temperature sensing, Water Resour. Res., 47, W07601, doi:10.1029/2010WR009482, 2011.

Read, T., Bour, O., Bense, V., Le Borgne, T., Goderniaux, P., Klepikova, M., Hochreutener, R., Lavenant, N., and Boschero, $\mathrm{V}$.: Characterizing groundwater flow and heat transport in fractured rock using fiber-optic distributed temperature sensing, Geophys. Res. Lett., 40, 2055-2059, doi:10.1002/grl.50397, 2013.

Sayde, C., Gregory, C., Gil-Rodriguez, M., Tufillaro, N., Tyler, S., Van de Giesen, N., English, M., Cuenca, R., and Selker, J. S.: Feasibility of soil moisture monitoring with heated fiber optics, Water Resourc. Res., 46, W06201, doi:10.1029/2009WR007846, 2010.

Selker, J., Van de Giesen, N., Westhoff, M., Luxemburg, W., and Parlange, M. B.: Fiber optics opens window on stream dynamics,
Geophys. Res. Lett., 33, L24401, doi:10.1029/2006GL027979, 2006.

Steele-Dunne, S. C., Rutten, M. M., Krzeminska, D. M., Hausner, M., Tyler, S. W., Selker, J., Bogaard, T. A., and Van de Giesen, N. C.: Feasibility of soil moisture estimation using passive distributed temperature sensing, Water Resour. Res., 46, W03534, doi:10.1029/2009WR008272, 2010.

Suárez, F., Aravena, J. E., Hausner, M. B., Childress, A. E., and Tyler, S. W.: Assessment of a vertical high-resolution distributedtemperature-sensing system in a shallow thermohaline environment, Hydrol. Earth Syst. Sci., 15, 1081-1093, doi:10.5194/hess15-1081-2011, 2011.

Tanimola, F. and Hill, D.: Distributed fibre optic sensors for pipeline protection, J. Nat. Gas Sci. Eng., 1, 134-143, doi:10.1016/j.jngse.2009.08.002, 2009.

Thomas, C., Kennedy, A., Selker, J., Moretti, A., Schroth, M., Smoot, A., Tufillaro, N., and Zeeman, M.: High-resolution fibre-optic temperature sensing: A new tool to study the twodimensional structure of atmospheric surface-layer flow, Bound.Lay. Meteorol., 142, 177-192, 2012.

Tyler, S. W., Selker, J. S., Hausner, M. B., Hatch, C. E., Torgersen, T., Thodal, C. E., and Schladow, S. G.: Environmental temperature sensing using raman spectra dts fiber-optic methods, Water Resour. Res., 45, W00D23, doi:10.1029/2008WR007052, 2009.

Van de Giesen, N., Steele-Dunne, S. C., Jansen, J., Hoes, O., Hausner, M. B., Tyler, S., and Selker, J.: Double-Ended Calibration of Fiber-Optic Raman Spectra Distributed Temperature Sensing Data, Sensors, 12, 5471-5485, 2012.

Van Emmerik, T., Rimmer, A., Lechinsky, Y., Wenker, K., Nussboim, S., and Van de Giesen, N.: Measuring heat balance residual at lake surface using distributed temperature sensing, Limnol. Oceanogr-Meth., 11, 79-90, 2013.

Vercauteren, N., Huwald, H., Bou-Zeid, E., Selker, J. S., Lemmin, U., Parlange, M. B., and Lunati, I.: Evolution of superficial lake water temperature profile under diurnal radiative forcing, Water Resour. Res., 47, W09522, doi:10.1029/2011WR010529, 2011.

Vogt, T., Schneider, P., Hahn-Woernle, L., and Cirpka, O. A.: Estimation of seepage rates in a losing stream by means of fiberoptic high-resolution vertical temperature profiling, J. Hydrol., 380, 154-164, doi:10.1016/j.jhydrol.2009.10.033, 2010.

Westhoff, M. C., Savenije, H. H. G., Luxemburg, W. M. J ., Stelling, G. S., van de Giesen, N. C., Selker, J. S., Pfister, L., and Uhlenbrook, S.: A distributed stream temperature model using high resolution temperature observations, Hydrol. Earth Syst. Sci., 11, 1469-1480, doi:10.5194/hess-11-1469-2007, 2007.

Westhoff, M. C., Gooseff, M. N., Bogaard, T. A., and Savenije, H. H. G.: Quantifying hyporheic exchange at high spatial resolution using natural temperature variations along a first-order stream, Water Resour. Res., 47, W10508, doi:10.1029/2010WR009767, 2011.

White, F.: Heat and Mass Transfer, Addison-Wesley series in mechanical engineering, Addison Wesley Publishing Company Incorporated, Reading, Massachusetts, USA, 718 pp., 1988.

WMO: WMO Guide to meteorological instruments and methods of observation, WMO-No. 8 (2008 edition, Updated in 2010), 2010.

Yilmaz, G. and Karlik, S. E.: A distributed optical fiber sensor for temperature detection in power cables, Sensor. Actuator. APhys., 125, 148-155, doi:10.1016/j.sna.2005.06.024, 2006. 